\title{
A detailed chemistry model for transient hydrogen and carbon monoxide catalytic recombination on parallel flat Pt surfaces implemented in an integral code
}

\author{
$\triangle$ Miguel A Jiménez ${ }^{(1)}$, Juan M Martín-Valdepeñas( ${ }^{(1)}$, Francisco Martín-Fuertes ${ }^{(1)}$, José A Fernández(2) \\ (1) Department of Nuclear Engineering \\ (2) Department of Energy and Fluid Mechanics Engineering \\ Escuela Técnica Superior de Ingenieros Industriales - Universidad Politécnica Madrid \\ C/ José Gutiérrez Abascal 2, E-28006 MADRID (Spain) \\ $\square$ Corresponding Author: Miguel A Jiménez \\ Consejo de Seguridad Nuclear \\ C/ Pedro Justo Dorado Dellmans 11, E-28040 MADRID (Spain) \\ Phone: +34 91 3300839, e-mail: majg@,csn.es
}

\begin{abstract}
A detailed chemistry model has been adapted and developed for surface chemistry, heat and mass transfer between $\mathrm{H}_{2} / \mathrm{CO} /$ air $/$ steam/CO mixtures and vertical parallel Pt-coated surfaces. This model is based onto a simplified Deutschmann reaction scheme for methane surface combustion and the analysis by Elenbaas for buoyancy-induced heat transfer between parallel plates. Mass transfer is treated by the heat and mass transfer analogy. The proposed model is able to simulate the $\mathrm{H}_{2} / \mathrm{CO}$ recombination phenomena characteristic of parallel-plate Passive Autocatalytic Recombiners (PARs), which have been proposed and implemented as a promising hydrogen-control strategy in the safety of nuclear power stations or other industries. The transient model is able to approach the warm-up phase of the PAR and its shut-down as well as the dynamic changes within the surrounding atmosphere. The model has been implemented within the MELCOR code and assessed against results of the Battelle Model Containment tests of the Zx series. Results show accurate predictions and a better performance than traditional methods in integral codes, i.e., empirical correlations, which are also much case-specific. Influence of CO present in the mixture on the PAR performance is also addressed in this paper.
\end{abstract}

\section{Introduction}

Catalytic $\mathrm{H}_{2} / \mathrm{O}_{2}$ reaction either onto surfaces or within porous media is the essential of a large variety of applications in industry. In particular, it has been proposed as a strategy for preventing the formation of potentially detonable or highly flammable atmospheres in nuclear containments. Several designs of Passive Autocatalytic Recombiners (PARs) have been commercialised by companies and implemented within actual facilities for hydrogen control in several countries. The exploration of PARs as a method for hydrogen removal in the nuclear reactor safety field has produced a large amount of literature that may be found elsewhere, and have deserved an extensive state-of-the-art review and analysis performed within the PARSOAR project (Bachellerie, 2002) as a basic reference.

The main feature of PARs is their passive behaviour, i.e. their ability to effectively recombine hydrogen driven by natural convection flow across the device powered by the heat generated in the self-sustained catalytic reaction at the surface (heterogeneous reaction). On the other hand, risk of reaction initiation in the gaseous phase (homogeneous reaction) must be considered as a shortcoming of this kind of devices under high hydrogen concentrations. For preventing this undesired effect, innovative PAR designs have been proposed for controlling high plate temperatures under hydrogen-rich environments (Bachellerie, 2002) and (Reinecke, 2004).

The different PAR designs conceived by several manufacturers feature the catalytic material, either distributed as a thin coating onto metallic planar surfaces (vertical parallel plates or surfaces), or within a ceramic porous matrix of pellets in cartridges. One of the most extended PAR concepts is that of a parallel-plate cartridge located at the lowermost face of a prismatic box (Figure 1). Plates are made of stainless steel and are covered by a thin Pt-based coating.

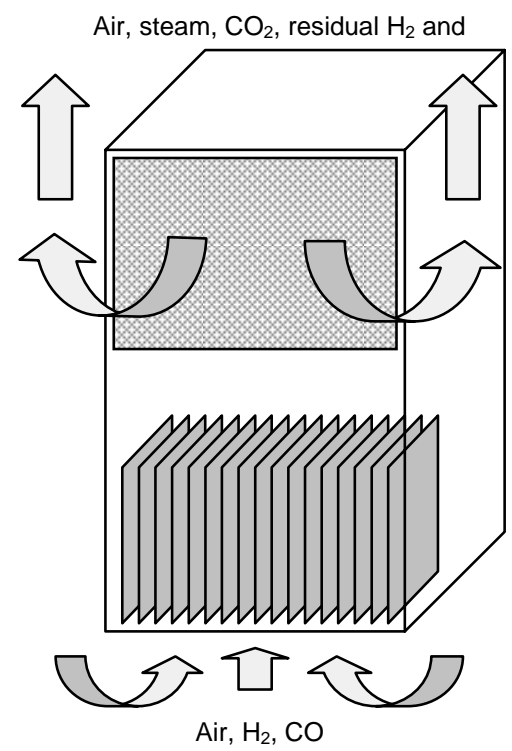

Figure 1. Sketch of a generic, parallel-plate Passive Autocatalytic Recombiner (PAR) and its performance. 


\begin{tabular}{|c|c|}
\hline \multicolumn{2}{|c|}{ Nomenclature } \\
\hline \multicolumn{2}{|c|}{ Constants } \\
\hline G & acceleration of gravity $\left(\mathrm{m} \mathrm{s}^{-2}\right)$ \\
\hline $\mathrm{R}$ & universal gas constant $\left(\mathrm{J} \mathrm{kg}^{-1} \mathrm{~K}^{-1}\right)$ \\
\hline \multicolumn{2}{|c|}{ Plate Parameters } \\
\hline $\mathrm{X}, \mathrm{Y}, \mathrm{Z}$ & Cartesian co-ordinates $(\mathrm{m})$ \\
\hline $\mathrm{x}, \mathrm{y}, \mathrm{z}$ & non-dimensional co-ordinates \\
\hline & vertical velocity $\left(\mathrm{m} \mathrm{s}^{-1}\right)$ \\
\hline $\mathrm{u}$ & non-dimensional vertical velocity \\
\hline $\mathrm{L}$ & plate vertical dimension (streamwise) (m) \\
\hline h & plate width $(\mathrm{m})$ \\
\hline $\mathrm{b}=2 \mathrm{a}$ & plate spacing or channel width (m) \\
\hline e & plate thickness $(\mathrm{m})$ \\
\hline$c_{p}$ & specific heat capacity $\left(\mathrm{J} \mathrm{kg}^{-1} \mathrm{~K}^{-1}\right)$ \\
\hline$\Gamma$ & surface density of sites in the catalyst $\left(\mathrm{mol} \mathrm{m}^{-2}\right)$ \\
\hline$a_{w}, a_{\infty}$ & surface area of plate, surroundings $\left(\mathrm{m}^{2}\right)$ \\
\hline \multicolumn{2}{|c|}{ Gas parameters } \\
\hline $\mathrm{T}$ & temperature $(\mathrm{K})$ \\
\hline $\mathrm{p}$ & pressure $(\mathrm{Pa})$ \\
\hline$C_{j}$ & concentration of species $j$ in the mixture (mole fraction) \\
\hline$c_{j}$ & $\begin{array}{l}\text { non-dimensional normalised concentration of } \\
\text { species } j \text { in the mixture }\end{array}$ \\
\hline $\mathrm{D}_{\mathrm{i}}$ & mass diffusivity of species $\mathrm{j}$ in the mixture $\left(\mathrm{m}^{2} \mathrm{~s}^{-1}\right)$ \\
\hline $\mathrm{W}_{\mathrm{j}}$ & molecular weight of species $\mathrm{j}\left(\mathrm{kg} \mathrm{mol}^{-1}\right)$ \\
\hline $\mathrm{k}$ & thermal conductivity $\left(\mathrm{W} \mathrm{m}^{-1} \mathrm{~K}^{-1}\right)$ \\
\hline \multicolumn{2}{|c|}{ Heat and Mass Transfer } \\
\hline $\operatorname{Pr}$ & Prandtl number \\
\hline $\mathrm{Sc}_{\mathrm{j}}$ & Schmidt number for species $j$ \\
\hline Gr' & modified Grashof number \\
\hline $\mathrm{Nu}$ & modified Nusselt number (based on Gr' and Pr) \\
\hline $\mathrm{Sh}_{j}^{\prime}$ & $\begin{array}{l}\text { modified Sherwood number for species } j \\
\text { (based on } G r^{\prime} \text { and } \mathrm{Sc}_{\mathrm{j}} \text { ) }\end{array}$ \\
\hline $\mathrm{Sh}^{*}{ }_{\mathrm{j}}$ & $\begin{array}{l}\text { modified Sherwood number for species } j \\
\text { (including the suction factor) }\end{array}$ \\
\hline$l_{1}$ & unitary length in the transient mass balance (m) \\
\hline Q & heat flux $\left(\mathrm{W} \mathrm{m}^{-2}\right)$ \\
\hline $\mathrm{E}_{\mathrm{b}}$ & black-body radiation energy flux ( $\left.\mathrm{W} \mathrm{m}^{-2}\right)$ \\
\hline $\mathrm{F}_{\mathrm{xy}}$ & view factor between surfaces $\mathrm{x}$ and $\mathrm{y}$ \\
\hline \multicolumn{2}{|c|}{ Chemical parameters } \\
\hline $\mathrm{k}_{\mathrm{i}}$ & constant of the i-th reaction \\
\hline$A_{i}$ & pre-exponential factor of the $\mathrm{i}$-th reaction (SI units) \\
\hline & activation energy $\left(\mathrm{J} \mathrm{mol}^{-1}\right)$ \\
\hline $\mathrm{S}_{\mathrm{ia}}$ & sticking coefficient of the $\mathrm{i}$-th reaction (adsorption) \\
\hline $\mathrm{q}_{\mathrm{i}}$ & enthalpy of i-th reaction $\left(\mathrm{J} \mathrm{mol}^{-1}\right)$ \\
\hline$t_{\mathrm{CO}}$ & delay time of CO entrainment in the mixture (s) \\
\hline \multicolumn{2}{|c|}{ Greek Symbols } \\
\hline$\vartheta$ & non-dimensional temperature \\
\hline$\rho$ & mass density $\left(\mathrm{kg} \mathrm{m}^{-3}\right)$ \\
\hline$\alpha$ & gas thermal diffusivity $\left(\mathrm{m}^{2} \mathrm{~s}^{-1}\right)$ \\
\hline$v$ & gas kinematic viscosity $\left(\mathrm{m}^{2} \mathrm{~s}^{-1}\right)$ \\
\hline$\varepsilon$ & emissivity \\
\hline$\theta_{j}$ & $\begin{array}{l}\text { normalised surface concentration of species } j \text { in the } \\
\text { surface }\end{array}$ \\
\hline$\omega_{\mathrm{i}}$ & rate of the $\mathrm{i}$-th reaction $\left(\mathrm{s}^{-1}\right)$ \\
\hline
\end{tabular}

\begin{tabular}{|ll|}
\hline \multicolumn{2}{|l|}{ Subscripts / Superscripts } \\
$\infty$ & bulk atmosphere \\
$\mathrm{w}$ & plate, wall \\
$\mathrm{g}$ & gaseous phase \\
$\mathrm{rad}$ & radiation \\
conv & convection \\
$\mathrm{i}$ & reaction number \\
$\mathrm{j}$ & species in the gas mixture / catalyst \\
$\mathrm{a}$ & adsorption \\
$\mathrm{d}$ & desorption \\
\hline
\end{tabular}

\section{Physical model of a parallel-plate recombiner}

Within an atmosphere at quiescent initial conditions, gas species in the surroundings are adsorbed into the catalytic coating by molecular diffusion and chemical reactions may start. Heat released by chemical reactions increase the plate temperature (warm-up phase), thereby modifying the reaction rates, heating the gas mixture between the plates and powering the flow up if the atmosphere composition is suitable for inducing self-sustained natural circulation. Presence of poisoning species, as well as unacceptable pressure losses through the device, might prevent PAR performance.

PAR device models for predictive safety analysis within integral computational codes have been traditionally based on empirical expressions correlating the main parameters: AECL (Bachellerie, 2002), FRA-ANP (Mohaved, 1994) and (Carcassi, 1997), NIS (Fischer, 1995), (Carcassi, 1997) and (Sher, 1997). Regardless of their advantages in practical applications, their applicability is restricted to situations similar to those in the experiments they have been derived from. Hence the interest of developing a mechanistic model able to explore in a deeper detail the complex processes occurring at the catalytic surface, which are intimately coupled to the heat and mass exchange between the plate itself and the gas stream. On the other hand, detailed theoretical models coupling the physical-chemical processes occurring are under development, and mostly implemented within detailed flow field characterisation provided by CFD codes.

In this paper, a detailed mechanistic model for simulation of the performance of a PAR device is introduced and its implementation into an integral code is explained. The model accounts for the different phenomena intervening in the recombiner, assuming that it is, essentially, a series of vertical flow channels delimited by vertical parallel plates:

1) Heat and mass transfer between the gaseous phase and the catalytic surface by natural convection,

2) Adsorption/desorption of species in the surface,

3) Surface chemical reactions and heat release,

4) Radiation heat exchange with the surroundings.

\subsection{Heat and mass transfer by natural convection between flat parallel surfaces}

The problem of heat transfer between a buoyant flow and a channel between two parallel plates was already solved by Elenbaas (Elenbaas, 1942). The main parameters intervening in the analysis are the following (Figure 2): $\mathrm{L}$ is the plate length in the vertical $\mathrm{X}$ direction and $\mathrm{b}=2 \mathrm{a}$ is the distance 
between plates, which are assumed to be at a uniform temperature $\mathrm{T}_{\mathrm{w}}$. Plate positions are therefore fixed by $\mathrm{Y}= \pm$ a. Governing equations of the heat and mass transfer between each of the plates and the fluid, assumed buoyant flow, are the following:

$$
\begin{aligned}
& \frac{\partial}{\partial X}(\rho U)=0 \\
& -v \frac{\partial^{2} U}{\partial Y^{2}}=g \frac{\Delta \rho}{\rho} \\
& U \frac{\partial T}{\partial X}=\alpha \frac{\partial^{2} T}{\partial Y^{2}} \\
& U \frac{\partial C_{j}}{\partial X}=D_{j} \frac{\partial^{2} C_{j}}{\partial Y^{2}}
\end{aligned}
$$

with the boundary conditions $\mathrm{U}=0, \mathrm{~T}=\mathrm{T}_{\mathrm{w}}$ and $\mathrm{C}_{\mathrm{j}}=\mathrm{C}_{\mathrm{j}}^{\mathrm{w}}$ at $\mathrm{Y}= \pm \mathrm{a}$. Gas properties far away before entering the channel are noted by $\mathrm{T}_{\infty}, \rho_{\infty}$ and $\mathrm{C}_{j}^{\infty}$.

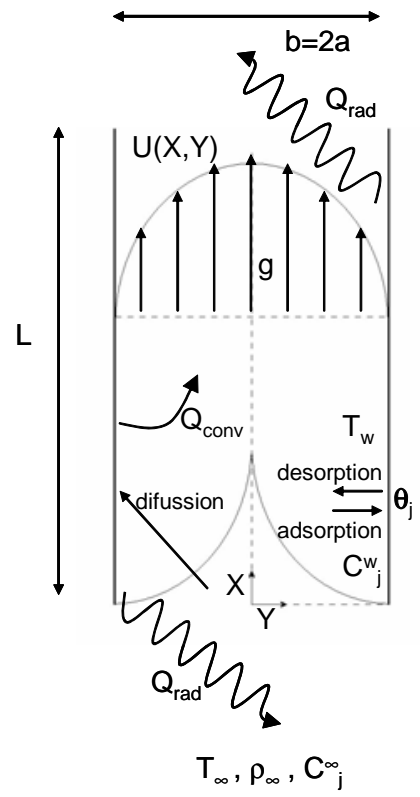

Figure 2. Schematics of the main parameters and phenomena of the parallelplate channel buoyant flow.

By introducing next dimensionless parameters:

$$
\begin{aligned}
& x=\frac{X}{L} ; y=\frac{Y}{a} ; \vartheta=\frac{T-T_{\infty}}{T_{w}-T_{\infty}} ; c_{j}=\frac{C_{j}-C_{j}^{\infty}}{C_{j}^{w}-C_{j}^{\infty}} ; \\
& u=\frac{U}{\left(\frac{a^{2} g \Delta \rho}{\rho v}\right)}
\end{aligned}
$$

the equation system eqs. (1-4) transforms as follows

$$
\begin{aligned}
& \frac{\partial u}{\partial x}=0 \\
& \frac{\partial^{2} u}{\partial y^{2}}=-1
\end{aligned}
$$

$u \frac{\partial \vartheta}{\partial x}=\frac{1}{G r^{\prime} \operatorname{Pr}} \frac{\partial^{2} \vartheta}{\partial y^{2}}$

$u \frac{\partial c_{j}}{\partial x}=\frac{1}{G r^{\prime} S c_{j}} \frac{\partial^{2} c_{j}}{\partial y^{2}}$

with equivalent boundary conditions $u=0, \vartheta=1$ and $c_{j}=1$ at $y= \pm 1$. Next are the dimensionless parameters in the equations:

$$
\begin{aligned}
& G r^{\prime}=\frac{a^{4} g \Delta \rho}{L \rho v^{2}} \\
& P r=\frac{v}{\alpha}=\frac{\mu c_{p}}{k} \\
& S c_{j}=\frac{v}{D_{j}}
\end{aligned}
$$

Equation system (5-8) features solutions like:

$$
\begin{aligned}
& u(x, y)=u(y)=c_{1}\left(1-y^{2}\right) \\
& \vartheta(x, y)=1-e^{-c_{2} x} \cos \left(\frac{\pi}{2} y\right) \\
& c_{j}(x, y)=1-e^{-c_{2}^{\prime} x} \cos \left(\frac{\pi}{2} y\right)
\end{aligned}
$$

being $c_{1}, c_{2}$ and $c_{2}$ integration constants. Solutions (12-14) may be introduced in eqs (5-8) and an analysis may be performed for the integrated heat and mass transfer within two asymptotical situations, illustrated on Figure 3, being the reader referred to (Elenbaas, 1942) for further details:

the infinitely long channel $(\mathrm{L} / \mathrm{b} \rightarrow \infty)$ : the fully-developed flow correspond to the boundary conditions at the channel such that the exiting gas stream properties are in equilibrium with the plate conditions $\left(\vartheta=1\right.$ and $c_{j}=1$ for $\left.\mathrm{x}=1\right)$.

the infinitely wide channel $(\mathrm{L} / \mathrm{b} \rightarrow 0)$ : essentially described by two separated boundary layers along each vertical solid plate $(\vartheta=1$ and $c_{j}=1$ for $x=1$ and $y=0, \vartheta=0$ and $c_{j}=0$ for $x=1$ and $\left.y= \pm 1\right)$. where, for the extremely long channel $(\mathrm{b} / \mathrm{L} \rightarrow 0)$, values of numbers $\mathrm{Nu}_{\mathrm{b}} \rightarrow\left(\mathrm{Gr}_{\mathrm{b}}{ }_{\mathrm{b}} \mathrm{Pr}\right) / 24$ and $\mathrm{Sh}_{\mathrm{b}} \rightarrow\left(\mathrm{Gr}_{\mathrm{b}}{ }_{\mathrm{b}} \mathrm{Sc}\right) / 24$. On the other asymptote for the extremely short channel $(\mathrm{b} / \mathrm{L} \rightarrow \infty)$, their expressions are $\mathrm{Nu}_{\mathrm{L}} \rightarrow 0.56(\mathrm{Gr} \mathrm{Pr})^{1 / 4}$ and $\mathrm{Sh}_{\mathrm{L}} \rightarrow 0.56(\mathrm{Gr}$ $\mathrm{Sc})^{1 / 4}$, as known for laminar flows along vertical plates.

From the analysis above, the following expressions are obtained for Nu' and Sh' (modified Nusselt and Sherwood numbers) valid for the full range of the aspect ratio L/b of the channel:

$$
N u_{b}^{\prime}=\frac{1}{24} G r_{b}^{\prime} \operatorname{Pr}\left(1-e^{-\frac{32}{G r_{b}^{\prime} P r}}\right)^{3 / 4}
$$

and, by the heat-mass transfer analogy:

$S h_{b, j}^{\prime}=\frac{1}{24} G r_{b}^{\prime} S c_{j}\left(1-e^{-\frac{32}{G r_{b}^{\prime} S C_{j}}}\right)^{3 / 4}$ 

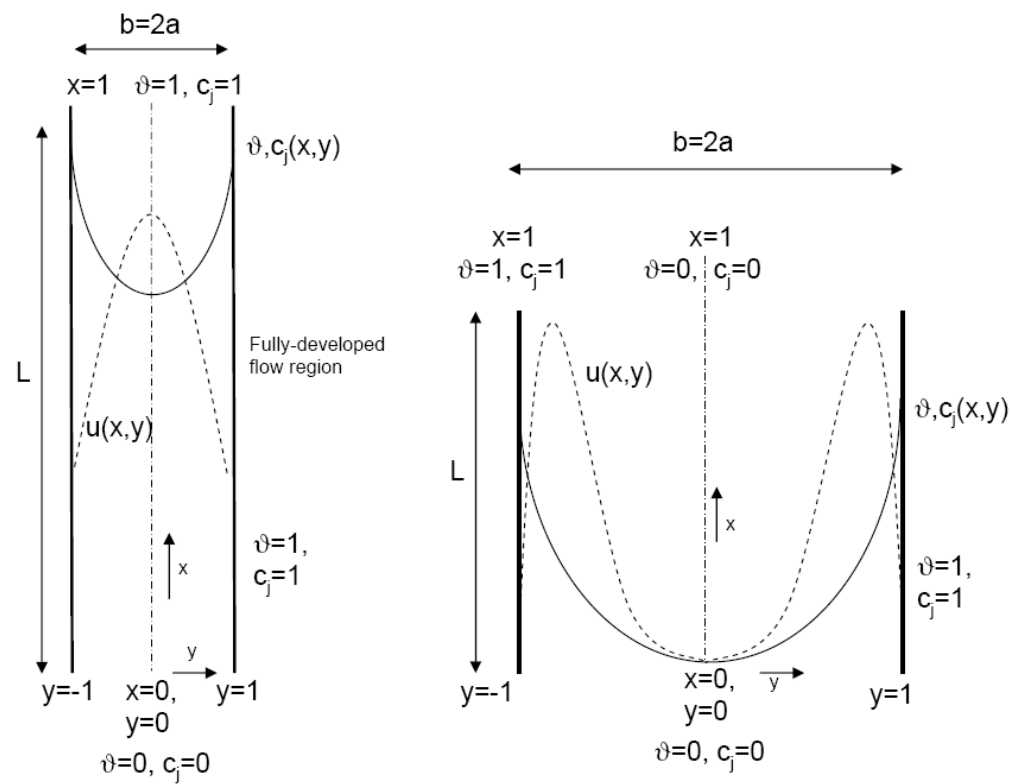

Figure 3. Solution profiles and boundary conditions for heat and mass transfer between two parallel vertical plates. Two asymptotes of the solution as taken from (Elenbaas, 1942): the infinitely long channel $(\mathrm{L}>>>$ b, left) vs the infinitely wide channel $(\mathrm{L}<<<\mathrm{b}$, right).

A final treatment of the radiation heat flux to the surroundings must be accounted for under high plate temperatures. By considering the geometry in Figure 2 as a two-surface enclosure, the radiation heat flux exiting the channel towards the surroundings through both of its ends may be calculated by:

$$
Q_{w \rightarrow \infty}^{r a d}=\frac{E_{b w}-E_{b \infty}}{\left[\left(1-\varepsilon_{w}\right) /\left(\varepsilon_{w} a_{w}\right)+1 /\left(a_{w} F_{w \infty}\right)+\left(1-\varepsilon_{\infty}\right) /\left(\varepsilon_{\infty} a_{\infty}\right)\right]}
$$

In terms of simplicity, the channel outlet is assumed to be under conditions near to those of the surroundings (true if the catalytic recombiner had not any housing) and reference values of emissivities $\varepsilon_{\mathrm{w}}$ and $\varepsilon_{\infty}$ have been taken equal to 0.5 as a reasonable value. View factor $\mathrm{F}_{\mathrm{w} \infty}$ corresponds to that within a prismatic cavity of height $L$, width $b$ and length $h$ (Incropera, 2001).

\subsection{Adsorption/desorption of species and surface chemistry}

The assumption that $\mathrm{H}_{2}$ (and eventually $\mathrm{CO}$ ) recombination with air takes place under temperatures low enough to ensure chemical reactions occur only at the catalytic surface (heterogeneous combustion) is applicable to most practical situations. Very complex mechanisms for the surface reactions amongst gaseous species $\left(\mathrm{O}_{2}, \mathrm{H}_{2}, \mathrm{H}_{2} \mathrm{O}\right.$ and eventually $\mathrm{CO}$ and $\mathrm{CO}_{2}$ ) occurring at the catalytic plate may be found in the literature. However, in this particular application, and provided that reduced mechanisms may be considered by neglecting reactions with long characteristic induction times (Mellado, 2002), the widely applied Deutschmann model for methane combustion (Deutschmann, 1996) will be adopted with some modifications. A reduced mechanism for the $\mathrm{H}_{2} / \mathrm{O}_{2}$ reactions (Mellado, 2002) and (Treviño, 1999) and a subset of the reactions involving carbon atoms $\mathrm{C}$ will constitute the chemical surface model.

\begin{tabular}{llccc}
\hline & \multicolumn{1}{c}{ Reaction } & S & A (SI units) & Eact (J/mol) \\
\hline $1 \mathrm{a}$ & $\mathrm{H}_{2}+2 \mathrm{Pt}(\mathrm{s}) \rightarrow 2 \mathrm{H}(\mathrm{s})$ & 0.046 & - & - \\
$1 \mathrm{~d}$ & $2 \mathrm{H}(\mathrm{s}) \rightarrow \mathrm{H}_{2}+2 \mathrm{Pt}(\mathrm{s})$ & - & $3.7 \times 10^{17}$ & $\mathrm{R}\left(8110-722 \theta_{\mathrm{H}}\right)$ \\
$2 \mathrm{a}$ & $\mathrm{O}_{2}+2 \mathrm{Pt}(\mathrm{s}) \rightarrow 2 \mathrm{O}(\mathrm{s})$ & $0.07(300 / \mathrm{T})$ & - & - \\
$2 \mathrm{~d}$ & $2 \mathrm{O}(\mathrm{s}) \rightarrow \mathrm{O}_{2}+2 \mathrm{Pt}(\mathrm{s})$ & - & $3.7 \times 10^{17}$ & $\mathrm{R}\left(25631-7220 \boldsymbol{\theta}_{\mathrm{O}}\right)$ \\
$3 \mathrm{a}$ & $\mathrm{H}_{2} \mathrm{O}+\mathrm{Pt}(\mathrm{s}) \rightarrow \mathrm{H}_{2} \mathrm{O}(\mathrm{s})$ & 0.75 & - & - \\
$3 \mathrm{~d}$ & $\mathrm{H}_{2} \mathrm{O}(\mathrm{s}) \rightarrow \mathrm{H}_{2} \mathrm{O}+\mathrm{Pt}(\mathrm{s})$ & - & $10^{13}$ & 40300 \\
4 & $\mathrm{H}(\mathrm{s})+\mathrm{O}(\mathrm{s}) \rightarrow \mathrm{OH}(\mathrm{s})+\mathrm{Pt}(\mathrm{s})$ & - & $3.7 \times 10^{17}$ & 11500 \\
5 & $\mathrm{H}(\mathrm{s})+\mathrm{OH}(\mathrm{s}) \rightarrow \mathrm{H}_{2} \mathrm{O}+\mathrm{Pt}(\mathrm{s})$ & - & $3.7 \times 10^{17}$ & 17400 \\
6 & $\mathrm{OH}(\mathrm{s})+\mathrm{OH}(\mathrm{s}) \rightarrow \mathrm{H}_{2} \mathrm{O}+\mathrm{O}(\mathrm{s})$ & - & $3.7 \times 10^{17}$ & 48200 \\
$7 \mathrm{a}$ & $\mathrm{CO}+\mathrm{Pt}(\mathrm{s}) \rightarrow \mathrm{CO}(\mathrm{s})$ & - & - \\
$7 \mathrm{~d}$ & $\mathrm{CO}(\mathrm{s}) \rightarrow \mathrm{CO}+\mathrm{Pt}(\mathrm{s})$ & - & $10^{13}$ & 125500 \\
$8 \mathrm{~d}$ & $\mathrm{CO}(\mathrm{s}) \rightarrow \mathrm{CO}+2 \mathrm{Pt}(\mathrm{s})$ & - & $3.7 \times 10^{13}$ & 20500 \\
9 & $\mathrm{CO}(\mathrm{s})+\mathrm{O}(\mathrm{s}) \rightarrow \mathrm{CO}(\mathrm{s})+\mathrm{Pt}(\mathrm{s})$ & $3.7 \times 10^{17}$ & 105000 \\
$14+$ & $\mathrm{C}(\mathrm{s})+\mathrm{O}(\mathrm{s}) \rightarrow \mathrm{CO}(\mathrm{s})+\mathrm{Pt}(\mathrm{s})$ & $10^{14}$ & 62800 \\
$14-$ & $\mathrm{CO}(\mathrm{s})+\mathrm{Pt}(\mathrm{s}) \rightarrow \mathrm{C}(\mathrm{s})+\mathrm{O}(\mathrm{s})$ & - & 184000
\end{tabular}


Desorption reactions are described by a general Arrhenius law $\mathrm{k}_{\mathrm{id}}=\mathrm{A}_{\mathrm{i}} \exp \left(-\mathrm{E}_{\mathrm{act}}^{\mathrm{i}} / \mathrm{RT}\right)$. On the other hand, species adsorption reactions will be modelled as usual by using sticking coefficients $\left(\mathrm{k}_{\mathrm{ia}}=\mathrm{S}_{\mathrm{ia}} /\left[\left(2 \pi \mathrm{RTW}_{\mathrm{j}}\right)^{1 / 2} \Gamma\right]\right)$, and the remaining catalytic reactions as general Langmuir-Hinshelwood type. The set of reactions and parameters applied are summarised on the Table 1 above.

Reactions are only considered to happen within the surface (heterogeneous reaction only) since temperature is assumed to be low enough in the gas stream. As a consequence of this assumption, concentration of the $\mathrm{OH}$ radical within the gas phase is neglected and the desorption reaction of the $\mathrm{OH}$ is thus ruled out from the mechanism. Influence of nitrogen in the surface reaction is neglected because of its extremely low sticking coefficient for adsorption. On the other hand, no adsorption reaction of the $\mathrm{CO}_{2}$ molecules is considered (they just desorb from the surface, and then are considered as inert species when into the gas phase). Additionally, intermediate $\mathrm{CH}_{\mathrm{n}}$ species are also ruled out from the mechanism, since they only appeared in the Deutschmann model as products of successive dissociations of the $\mathrm{CH}_{4}$ molecule, which is not present in the gas mixture under consideration. Finally, activation energies of the $\mathrm{H}_{2}$ and $\mathrm{O}_{2}$ desorption reactions are assumed to be proportional to their respective surface concentrations, as proposed by (Hellsing, 1991).

\section{Numerical model}

The numerical model developed starts from the heat and mass transfer coupling between the gas stream and the plates with the adsorption/desorption of species at the surface and the chemical reactions. This is formulated by simple balances that, under transient conditions, may be expressed by the following set of 14 differential equations:

$$
\begin{aligned}
& \frac{d \theta_{v}}{d t}=-2\left(\omega_{1}+\omega_{2}\right)-\omega_{3}+\omega_{4}+\omega_{5}-\omega_{7}+\left(\omega_{8}+\omega_{9}+\omega_{14}\right) \\
& \frac{d \theta_{H}}{d t}=2 \omega_{1}-\omega_{4}-\omega_{5} \\
& \frac{d \theta_{O}}{d t}=2 \omega_{2}-\omega_{4}+\omega_{6} \\
& \frac{d \theta_{v a p}}{d t}=\omega_{3}+\omega_{5}+\omega_{6} \\
& \frac{d \theta_{O H}}{d t}=\omega_{4}-\omega_{5}-2 \omega_{6} \\
& \frac{d \theta_{C O}}{d t}=\omega_{7}-\omega_{9}+\omega_{14} \\
& \frac{d \theta_{C O_{2}}}{d t}=-\omega_{8}+\omega_{9} \\
& \frac{d \theta_{C}}{d t}=-\omega_{14} \\
& \frac{d C_{H_{2}}^{w}}{d t}=\frac{1}{l_{1}}\left[\frac{S h_{b, H_{2}}^{*} D_{H_{2}}}{b}\left(\frac{C_{H_{2}}^{\infty} \bar{W}^{w}}{\bar{W}^{\infty}}-C_{H_{2}}^{w}\right)-\frac{\bar{W}^{w} \Gamma}{\rho^{w}} \omega_{1}\right] \\
& \frac{d C_{O_{2}}^{w}}{d t}=\frac{1}{l_{1}}\left[\frac{S h_{b, O_{2}}^{*} D_{O_{2}}}{b}\left(\frac{C_{O_{2}}^{\infty} \bar{W}^{w}}{\bar{W}^{\infty}}-C_{O_{2}}^{w}\right)-\frac{\bar{W}^{w} \Gamma}{\rho^{w}} \omega_{2}\right]
\end{aligned}
$$

$$
\begin{aligned}
& \frac{d C_{\text {vap }}^{w}}{d t}=\frac{1}{l_{1}}\left[\frac{S h_{b, v a p}^{*} D_{\text {vap }}}{b}\left(\frac{C_{\text {vap }}^{\infty} \bar{W}^{w}}{\bar{W}^{\infty}}-C_{\text {vap }}^{w}\right)-\frac{\bar{W}^{w} \Gamma}{\rho^{w}} \omega_{3}\right] \\
& \frac{d C_{C O}^{w}}{d t}=\frac{1}{l_{1}}\left[\frac{S h_{b, \mathrm{CO}}^{*} D_{\mathrm{CO}}}{b}\left(\frac{C_{C O}^{\infty} \bar{W}^{w}}{\bar{W}^{\infty}}-C_{C O}^{w}\right)-\frac{\bar{W}^{w} \Gamma}{\rho^{w}} \omega_{7}\right] \\
& \frac{d C_{C O_{2}}^{w}}{d t}=\frac{1}{l_{1}}\left[\frac{S h_{b, \mathrm{CO}_{2}}^{*} D_{\mathrm{CO}_{2}}}{b}\left(\frac{C_{C O_{2}}^{\infty} \bar{W}^{w}}{\bar{W}^{\infty}}-C_{C O_{2}}^{w}\right)-\frac{\bar{W}^{w} \Gamma}{\rho^{w}} \omega_{8}\right] \\
& \frac{d T_{w}}{d t}=\frac{1}{\left(\frac{e}{2} \rho C_{p}\right)^{\text {plate }}}\left[\Gamma \sum_{i} q_{i} \omega_{i}-\frac{N u_{b}^{\prime} k_{g}^{w}}{b}\left(T_{w}-T_{\infty}\right)-q_{w \rightarrow \infty}^{r a d}\right]
\end{aligned}
$$

where the RHSs of eqs (26-30) introduce a mass balance per unit area and unit time between the mass diffusion and the mass source by surface chemical reactions. On the other hand, the LHSs on these equations represent the stream mass fraction variation per unit volume and unit time. Hence, both sides are scaled by a unitary length $l_{1}$ in the transient regime.

The equation system (18-31) consists of 14 equations, involving 14 variables, namely $\theta_{j=1, \ldots, 8}$ (8 variables), the $\mathrm{C}_{\mathrm{j}=1, \ldots, 5}$ (5 variables) and the gas temperature next to the wall, which is assumed to be equal to the wall temperature $T_{w}$. Definition of $\theta_{j}$ is such that $\Sigma_{j=1 \ldots 8} \theta_{j}=1$ (being $\theta_{v}$ the fraction surface concentration of void sites) and that of the species concentrations $\Sigma_{\mathrm{j}=1 \ldots 5} \mathrm{C}_{\mathrm{j}}=\left(1-\mathrm{Cw}_{\mathrm{N} 2}\right)$.

Sherwood numbers $\mathrm{Sh}_{\mathrm{j}}{ }_{\mathrm{j}}$ are corrected by the suction factors (Bird, 1960) to account for undiluted species, and gas properties are evaluated by using standard tables from the CEA code (McBride, 1996) and routines by (MartínValdepeñas, 2004). Reaction rates $\omega_{i}$ in the equations are functions of these variables, since:

$$
\begin{aligned}
& \omega_{1}=k_{1 a} C_{H_{2}}^{w} p \theta_{v}-k_{1 d} \theta_{H}^{2} \\
& \omega_{2}=k_{2 a} C_{O_{2}}^{w} p \theta_{v}^{2}-k_{2 d} \theta_{O}^{2} \\
& \omega_{3}=k_{3 a} C_{v a p}^{w} p \theta_{v}-k_{3 d} \theta_{v a p} \\
& \omega_{4}=k_{4} \theta_{H} \theta_{O} \\
& \omega_{5}=k_{5} \theta_{H} \theta_{O H} \\
& \omega_{6}=k_{6} \theta_{O H}^{2} \\
& \omega_{7}=k_{7 a} C_{C O}^{w} p \theta_{v}^{2}-k_{7 d} \theta_{C O} \\
& \omega_{8}=k_{8} \theta_{C O_{2}} \\
& \omega_{9}=k_{9} \theta_{C O} \theta_{O} \\
& \omega_{14}=k_{14+} \theta_{C} \theta_{O}-k_{14-} \theta_{C O} \theta_{v}
\end{aligned}
$$

Even though the stoichiometry of the hydrogen adsorption reaction requires two void sites in the catalyst, a reaction index (the exponent) for $\theta_{\mathrm{v}}$ in eq. (32) equal to 1 describes properly the ignition processes of catalysed $\mathrm{H}_{2} / \mathrm{O}_{2}$ reactions, as concluded by (Rinnemo, 1997) and (Mellado, 2002) when exploring the initial conditions $\theta_{\mathrm{H} 2}=1$ or $\theta_{\mathrm{O} 2}=1$. On the other hand, the $\mathrm{CO}$ molecule would in principle require only one void site, but the kinetics of $\omega_{7}$ is described by a reaction 
index 2 better than 1 in eq. (38) (Deutschmann, 1996), (Treviño, 1999).

The system eqs. (18-31) may be treated as a non-linear system of differential equations:

$$
\frac{d X}{d t}=F(X)
$$

being $\mathrm{X}$ the vector of variables and $\mathrm{F}$ the function matrix of the system eqs. (18-31). Since the F matrix does not represent a linear function of the elements in $\mathrm{X}$, an implicit solution scheme $\left(X_{n+1}=X_{n}+\Delta t \quad F\left(X_{n+1}\right)\right)$ is not directly applicable. However, if a short enough time step $\Delta \mathrm{t}$ is considered, the following first-order approach may be followed (Meglicki, 2001):

$F\left(X_{n+1}\right) \approx F\left(X_{n}\right)+\left.\frac{\partial F}{\partial X}\right|_{X_{n}}\left(X_{n+1}-X_{n}\right)$

being $\mathrm{J}=(\partial \mathrm{F} / \partial \mathrm{X})$ the Jacobian matrix of the system eqs. (1831). By introducing eq. (43) into a general implicit scheme the following semi-implicit scheme yields:

$$
X_{n+1}=X_{n}+\left[\mathrm{I}-\left.\Delta t \frac{\partial F}{\partial X}\right|_{X_{n}}\right]^{-1} \Delta t F\left(X_{n}\right)
$$

which requires the inversion of the matrix $(\mathbf{I}-\Delta t \mathbf{t})$, being $\mathbf{I}$ the identity matrix. This inversion has been achieved by the use of the DGETRF, DGETRI, DGEMV and auxiliary libraries of the LAPack collection (LAPack, 2000). A standalone version of the model has been produced in order to perform several parametric analysis and validation exercises, and has also been implemented in the integral severe accident code MELCOR 1.8.5 (Gauntt, 2000), as will be introduced in next sections.

\section{Parametric analyses and validation exercises}

\subsection{Influence of heat transfer parameters}

Influence of the heat transfer parameters on the recombiner performance is shown on Figures 4, 5 and 6, showing the behaviour of a standard Siemens FR-90/320 recombiner under fixed external conditions $\left(\mathrm{p}=100300 \mathrm{~Pa}, \mathrm{~T}_{\infty}=356 \mathrm{~K}\right.$, $\left.\mathrm{C}_{\text {vap }}^{\infty}=0.318, \mathrm{C}_{\mathrm{H} 2}^{\infty}=0.0526\right)$. These 'Reference' conditions correspond to an experimental situation found during the test BMC-Zx02 for PAR\#3 (Kanzleiter, 1997a), where the hydrogen recombination peak rate was measured up to 378 $\mathrm{g} / \mathrm{h}$. 'Reference' curve in Figure 4 shows the transient hydrogen recombination rate predicted by the standalone model introduced in this paper. The PAR warm-up phase starts from $\mathrm{t}=0$, as long as $\mathrm{H}_{2}$ is progressively being adsorbed onto the catalyst, initially fully occupied by $\mathrm{O}$ atoms $\left(\theta_{\mathrm{O}} \approx 1\right)$, see Figure 6. After some 60 seconds, concentration of $\mathrm{H}$ radicals in the surface is enough to start the chemical reaction by compensating the heat losses, very slowly at the beginning, but showing a rapid increase 1000 seconds after. The consequent increase in plate temperature, shown on Figure 5, promotes the formation of void sites (increasing $\boldsymbol{\theta}_{\mathrm{v}}$ ) by desorption of $\mathrm{O}$ radicals, as Figure 6 illustrates. A large fraction of void sites at the surface is indicative of ignited reactions, since vacant places are needed for the interchange of species between the gas stream and the catalyst. Steadystate recombination rate stabilises at $374 \mathrm{~g} / \mathrm{h}$, very close to the experimental value.

Influence of heat transfer parameters is depicted in Figures 4 and 5. The 'Reference' situation is compared to other ones in which heat transfer by radiation or convection are either not considered, transferred heat flux is multiplied by a factor of 2 in both phenomena, or radiation heat flux is considered to amount one half of the 'Reference'. Analysed results from model are the hydrogen recombination rate and the plate temperature. Main conclusions of this analysis show the following:

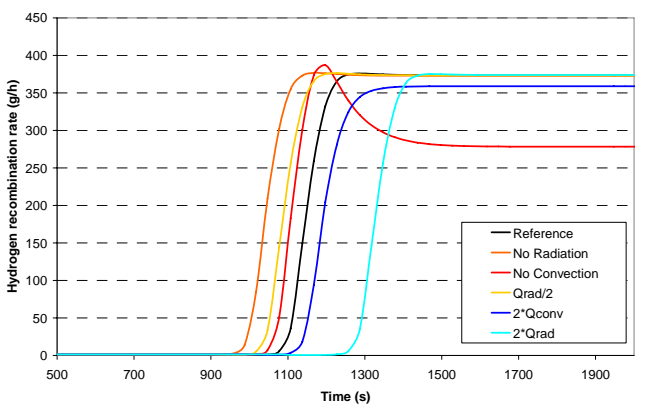

Figure 4. Influence of main parameters for radiation/convection heat transfer on the transient recombination rate of a Siemens FR 90/320 PAR under 'Reference' conditions.

1) Variation cases in which heat losses from the surfaces are lowered (namely, the NoRadiation, $\mathrm{Q}_{\mathrm{rad}} / 2$ and NoConvection) lead to an anticipated reaction startup but to a steady-state recombination rate at a higher plate temperature. Mostly in the NoConvection case, whose steady-state recombination rate remains well below the 'Reference' curve.

2) On the other hand, increased heat losses $\left(2 * Q_{\text {conv }}, 2^{*} Q_{\text {rad }}\right)$ cause a delayed startup, but leading to a steady-state recombination rate at a lower plate temperature. Once again, the enhanced convection exercise leads to a steady state recombination rate lower than the 'Reference' one.

3) As a conclusion, radiation heat transfer seems to influence the recombiner startup processes (surface chemistry) more than the long-term performance (steady-state plate temperature), which is mostly influenced by heat convection.

Simulations of the variation cases show the following results: 1) Reaction rate at the maximum: all of the radiation variation cases show values about the 'Reference' $374 \mathrm{~g} / \mathrm{h}$. The convective variation cases show steady-state rates ranging from $359 \mathrm{~g} / \mathrm{h}$ in the $2^{*} \mathrm{Q}_{\text {conv }}$ case to $278 \mathrm{~g} / \mathrm{h}$ (after peaking up to $387 \mathrm{~g} / \mathrm{h}$ ) in the NoConvection simulation.

2) Time to reach the maximum reaction rate: ranging from $1140 \mathrm{~s}$ (NoRadiation) to $1450 \mathrm{~s}\left(2 * \mathrm{Q}_{\mathrm{rad}}\right)$. Reference value: $1257 \mathrm{~s}$.

3) Steady-state recombination rate: from $278 \mathrm{~g} / \mathrm{h}$ (NoConvection) through to $374 \mathrm{~g} / \mathrm{h}\left(2^{*} \mathrm{Q}_{\mathrm{rad}}\right)$. Reference value: $374 \mathrm{~g} / \mathrm{h}$. It is worth mentioning that the $\mathrm{Zx02}$ measurement in this situation was $378 \mathrm{~g} / \mathrm{h}$, but under quasi steady-state conditions.

4) Steady-state plate temperature: from $680 \mathrm{~K}\left(2^{*} \mathrm{Q}_{\text {conv }}\right)$ through to $1436 \mathrm{~K}$ (NoConvection), with a 'Reference' value 
of $838 \mathrm{~K}$. No experimental values have been found for the plates themselves but, for the PAR housing and outlet, they reached about $640 \mathrm{~K}$ in the test (Kanzleiter, 1997a). Additionally, complementary analyses have shown that plate temperature predicted by this model is in fair agreement with numerical (Heitsch, 2000), experimental or analytical data
(Reinecke, 2004) reported by other authors. Accurate prediction of plate temperature is considered convenient in order to establish the possibility of starting ignition in the homogeneous phase, as has been evidenced in some experiments (Kanzleiter, 1997c), (Blanchat, 1998).

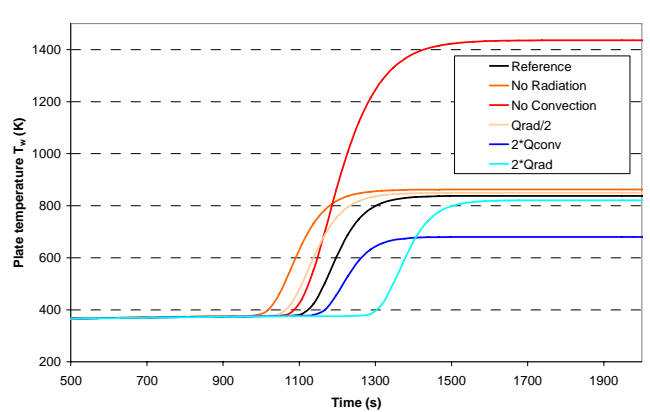

Figure 5. Influence of main parameters for radiation/convection heat transfer on the transient plate temperature of a Siemens FR 90/320 PAR within the 'Reference' mixture.

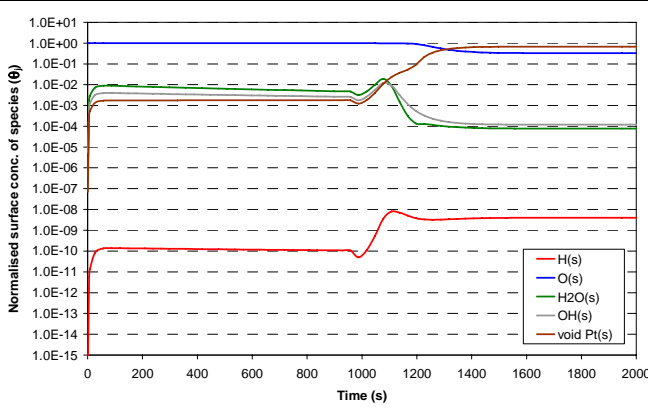

Figure 6. Transient species surface concentrations $\theta_{\mathrm{j}}$ adsorbed onto the catalytic plate for fixed external 'Reference' conditions.

\subsection{Implementation into the MELCOR code}

With the aim of extensive model applicability to severe accident simulations activities, coupling of this model has been performed with the integral severe accident code MELCOR (Gauntt, 2000), as an extension to its corresponding PAR module in the ESF package. By reasons of consistency with the variable database in the code, the numerical has been transformed into real variable precision, hence by using the SGETRF, SGETRI, SGEMV, etc... libraries from LAPack. Model coupling has been performed with minimum modifications, in order to keep the current abilities of MELCOR, in such way that variable input needed for the proposed model (gas composition in terms of mole fractions, temperature and pressure) are the same as the

currently implemented model by Fischer (Gauntt, 2000) and (Fischer, 1995). Specific parameters needed for the model proposed (number of plates, $\mathrm{L}, \mathrm{b}, \mathrm{h}, \mathrm{e}, \rho_{\text {plate }}, \mathrm{c}_{\mathrm{p}}$ ) are introduced via MELCOR input file with the inclusion of a new flag IPROPT $<0$. Even though the model herein could provide with much more detailed information of the PAR phenomena, just recombination rates have been made available so far for code output and result plotting. Mass consumption and production are passed to the $\mathrm{CVH}$ package as usual mass sources, for consistency with the internal code database.

\subsection{Model validation with tests at the Battelle Model Containment (BMC)}

Solutions of the system eqs. (18-31) have been obtained by the standalone model for fixed external conditions in order to test the solutions for the recombination rate under steady-state external conditions compared to experimental results from the literature in the Battelle Model Containment (BMC) (Kanzleiter, 1997a,b) and (Heitsch, 2000). Results are summarised on Figure 7 , in which recombination rate $(\mathrm{g} / \mathrm{h})$ is normalised to the unit area of catalyst to make different experiments comparable. Results are represented as a function of hydrogen concentration in $\mathrm{mol} / \mathrm{m}^{3}$ in order to eliminate the effect of steam. The proposed model predicts properly recombination rates in the intermediate range (equivalent to $4 \%-5 \%$ of $\left.\left[\mathrm{H}_{2}\right]\right)$. Predictions, however, deviate from the experimental data mainly in the end of low hydrogen concentrations, where recombination rates are overestimated. However, test conditions simulated are usually far from stationary, mainly in the low concentration ranges, when the device is experiencing shutdown. Correlation models from University of Pisa (power law and linear fits) (Carcassi, 1997) and FRA-ANP (Mohaved, 1994) are also shown for comparison. All models show a clear divergence in the high hydrogen concentration limit.

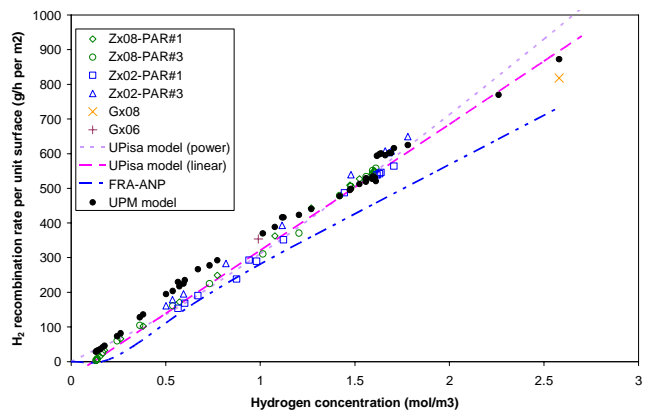

Figure 7. Comparison of the standalone model by UPM with experimental data from various experiments at the BMC and models from University of Pisa and FRA-ANP.

After model implementation within the MELCOR code, validation calculations have been performed in order to check the coupling of the full transient model with the main calculation flow by MELCOR. Transient simulations of the Zx02 and Zx08 experiments at the BMC have been applied in this way for testing the dynamic behaviour of the new model and comparing results with existing models, based on correlations.

The Zx series of tests was performed at the Battelle Model Containment in Germany (Kanzleiter, 1997 a, b and c). It is a 
multi-compartment containment mock-up, with $640 \mathrm{~m}^{3}$ of free volume, sketched on Figure 8.

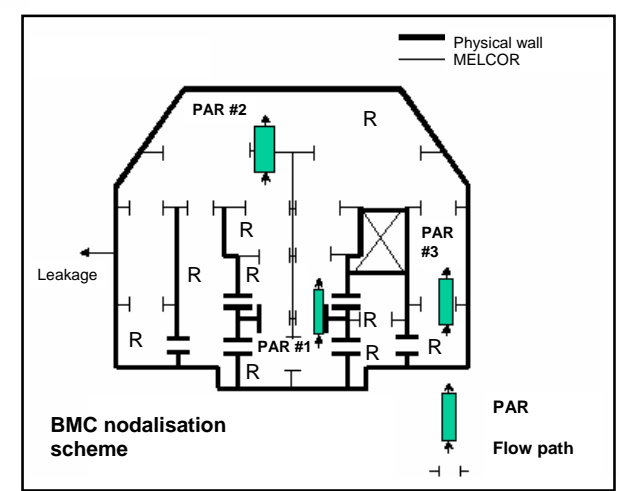

Figure 8. Diagram of the Battelle Model Containment (BMC) nodalisation scheme for the MELCOR code, showing the locations of PARs \#1, \#2 and \#3. Gas injection is located below PAR\#1 in the compartment R3, at the centre-bottom of the containment, for tests $\mathrm{Zx} 02$ and $\mathrm{Zx} 08$.

Three PARs were setup during these tests: PAR\#1 is located between compartments R3 and R1, just above the steam/hydrogen sources located at the centre bottom of the containment, PAR\#2 at the containment dome compartment $\mathrm{R} 9$, and PAR\#3 is located in the peripheral lower compartment R9. PARs \#1 and \#3 correspond to Siemens design parallel plate recombiners. PAR\#1 consists of 15 plates of dimensions $0.14 \times 0.13 \mathrm{~m}$, spaced $0.01 \mathrm{~m}$, and made of stainless steel coated by Pt. PAR\#3 has the same properties, but is 32 plates in size. PAR\#2 is of NIS design, where catalyst consists of ceramic pellets embedded within cartridges, hence not directly simulable by the model from UPM. It has been modelled in all calculations by the current

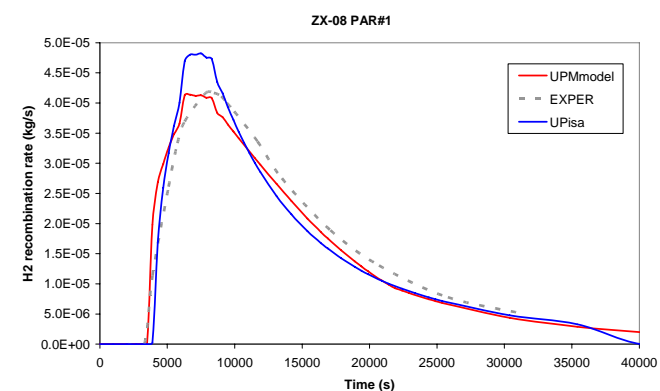

Figure 9. Comparison of UPM and UPisa models with the experimental data of Test Zx08, PAR\#1.

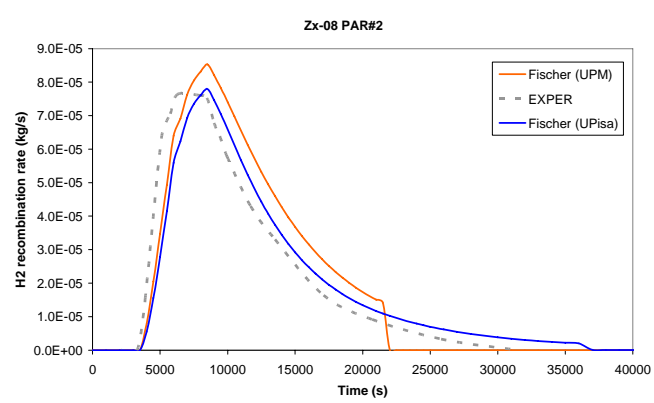

Figure 11. Comparison of the default Fischer model for PAR\#2 with the experimental data of Test Zx08, when applied with UPM and UPisa models for PARs \#1 and \#3.
Fischer model implemented in MELCOR, in order to avoid further model effects in this PAR. In the absence of detailed specifications, surface site density of the catalyst in PARs \#1 and \#3 has been assumed to equal $\Gamma=2 \times 10^{-5} \mathrm{~mol} / \mathrm{m}^{2}$, typical value found in the literature.

\subsubsection{The BMC Zx08 Test}

The Zx08 test (Kanzleiter, 1997b) was simulated first by reasons of simplicity. Hydrogen injection is performed in the central lower compartment (R3) just below PAR\#1 (Figure 8). No steam is injected, since the test was conceived to evolve within a dry air $/ \mathrm{H}_{2}$ mixture under atmospheric conditions. Nearly uniform homogenisation of the atmosphere was observed during this test, therefore leading to an optimal applicability of the MELCOR code.

Results for PARs \#1 and \#3 (parallel plate design) are introduced on next figures. Figure 9 shows the prediction of the PAR\#1 performance $(\mathrm{kg} / \mathrm{s})$ during the test. Quite a good agreement is shown with experimental values, but recombination rate is overpredicted after the rapid startup. Maximum value is predicted but anticipated quite early. During the descending slope, recombination rate stands below experiment. This might be an effect of the early intense hydrogen depletion occurred during the PAR warm-up phase. For comparison, the model from University of Pisa (Carcassi, 1997) has also been simulated through the usage of MELCOR Control Functions. The same behaviour is observed for the UPisa model, with even a larger deviation of the maximum. The UPisa model is basically a correlation in which the hydrogen recombination rate is essentially a power or a linear function of the hydrogen concentration in $\left(\mathrm{mol} / \mathrm{m}^{3}\right)$, as Figure 7 anticipated.

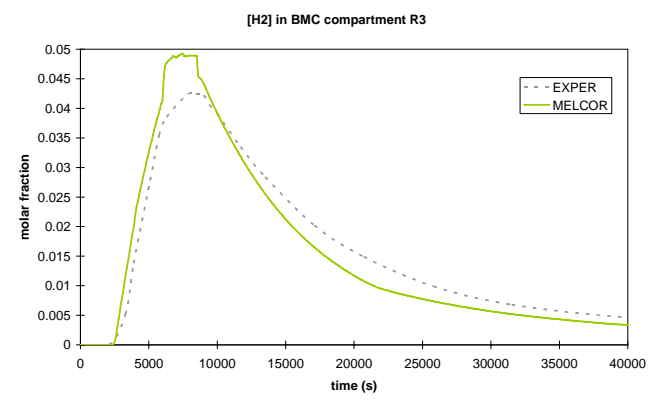

Figure 10. Comparison of the $\left[\mathrm{H}_{2}\right]$ in the BMC compartment $\mathrm{R} 3$ as measured at the $\mathrm{Zx} 08$ experiment, vs its evolution as predicted with the MELCOR code.

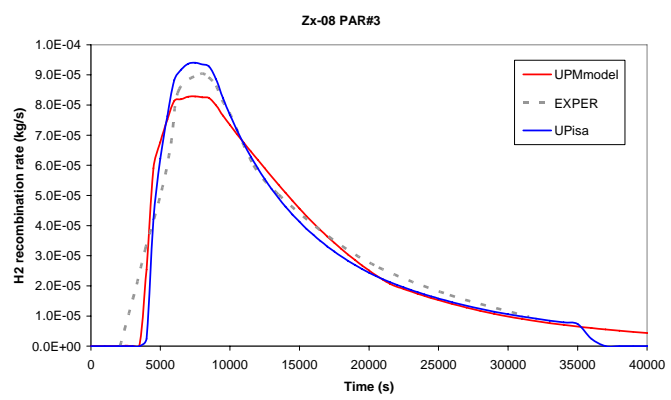

Figure 12. Comparison of UPM and UPisa models with the experimental data of Test Zx08, PAR\#3. 
In models based on correlations, a threshold value of concentration must be reached for the reaction to start (typically, in the order of $2 \%$ in mole fraction) and is usually supplied by the user. Such initial over-predictions of the hydrogen recombination rate for both models could rather be attributable to MELCOR code overestimated local hydrogen concentrations at locations close to the release source during hydrogen injection, as Figure 10 shows. This is a common shortcoming of lumped-parameter codes when applied within small compartments hosting stable jets induced by intense mass release sources (Bachellerie, 2002) and (Mohaved, 1999).

Figure 11 shows the recombination rate for PAR\#2, located at the dome region. This is of a pellet cartridge design, therefore the UPM model is not applicable, but the current Fischer model in MELCOR. Figure 11 shows that both the UPisa and UPM models feature a certain delay in the recombiner response when compared to experiment. This could be a consequence of the large hydrogen depletion predicted for the PAR\#1 located upstream. The same reason could be the explanation for the very late startup shown by both models regarding PAR\#3 performance on Figure 12. PAR\#3 is the last one located along the hydrogen pathway, hence hydrogen concentration will take more time to reach the threshold value to start stable reaction in the MELCOR simulation.

\subsubsection{The BMC Zx02 Test}

The Zx02 test (Kanzleiter, 1997a) performed essentially like Zx08, with one exception: the presence of steam in the atmosphere. Building geometry is the same, as are PARs \#1 and \#3. PAR\#2 was provided with a chimney to enhance buoyancy. Figure 13 shows the comparison for PAR\#1. A short startup peak at about $1500 \mathrm{~s}$ is observed in both models but not in the experiment.

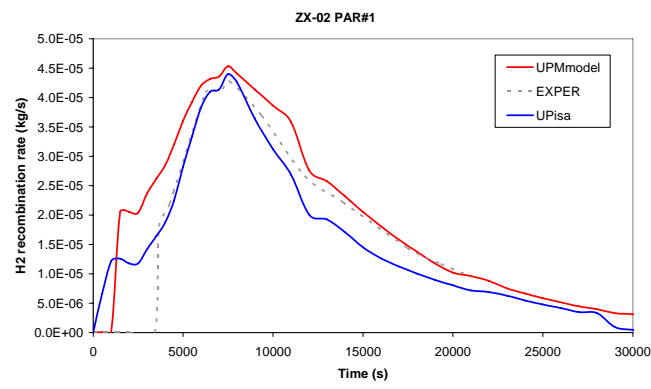

Figure 13. Comparison of UPM and UPisa models with the experimental data of Test Zx02, PAR\#1.

This slight deviation in the MELCOR code predictions could indicate that the hydrogen concentration is close to the limit to start reaction, as already mentioned. Unfortunately, this overestimation has influenced the results at the other PARs. Figures 14 and 15 show the effect of a rapid migration of hydrogen throughout the full building, since PARs \#1 and \#3 hardly show any delay in their startup. This could be attributable to the pre-existing circulation pattern in the containment due to the steam release and condensation (curves EXPER look the same in both plots).

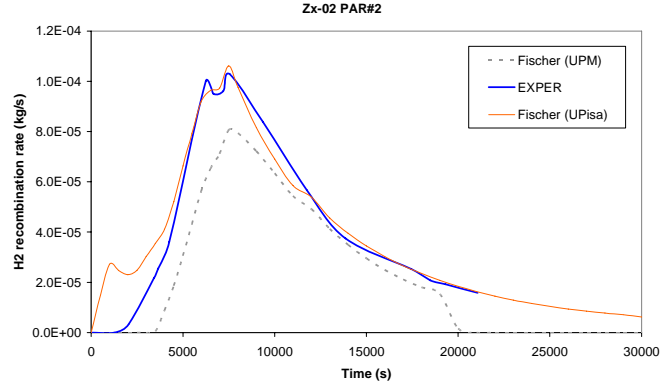

Figure 14. Comparison of the default Fischer model for PAR\#2 with the experimental data of Test $\mathrm{Zx02}$, when applied with UPM and UPisa models for PARs \#1 and \#3.

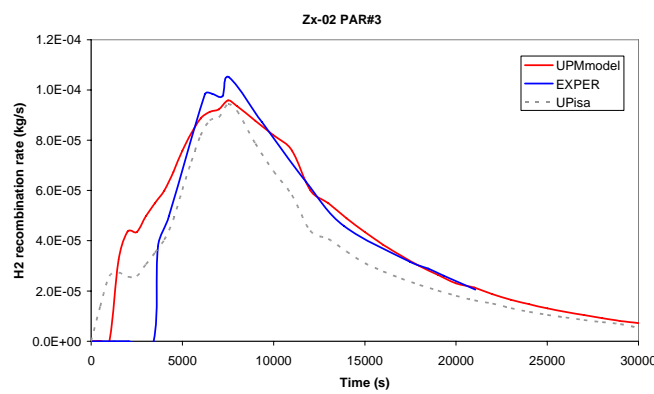

Figure 15. Comparison of UPM and UPisa models with the experimental data of Test Zx02, PAR\#3.

\subsection{Effect of the presence of $\mathrm{CO}$ in the mixture}

Because of the large sticking coefficient of $\mathrm{CO}$ compared to the other adsorbed species and its high activation energy for desorption, the presence of $\mathrm{CO}$ in the mixture would be able to poison the catalytic surface, therefore preventing the reaction to occur under low temperature conditions (frozen or weak reaction). However, under certain circumstances, ignition could appear during short time periods at temperatures as low as $450 \mathrm{~K}$ (Rinnemo, 1997). This could be an explanation for the spontaneous $\mathrm{CO}$ recombination reported during PAR qualification H2PAR tests (Kumar, 2000) and (Bachellerie, 2002). On the other hand, if plate temperature $T_{w}$ is high enough, reaction rate $\omega_{7}$ for the CO adsorption/desorption in eq. (38) could be displaced towards $\mathrm{CO}$ desorption thus allowing the formation of void sites and maintaining the reaction, controlled by the adsorption rate of $\mathrm{O}_{2}$. Finally, when surface temperature is above $900 \mathrm{~K}$, reaction changes and its rate is limited by the $\mathrm{CO}$ adsorption. In these conditions, extinction could be reached when the surface cools down and the fraction surface concentrations reach values $\theta_{\mathrm{CO}}, \theta_{\mathrm{O}} \sim 1$ (Treviño, 2000).

For studying the effect of the presence of $\mathrm{CO}$ in the gas mixture, a parametric study with the standalone module has been applied based again on the initial conditions selected for the analysis of heat transfer parameters, the 'Reference' mixture in Section 5.1 (namely $\mathrm{p}=100300 \mathrm{~Pa}, \mathrm{~T}_{\infty}=356 \mathrm{~K}$, $\left.\mathrm{C}_{\text {vap }}^{\infty}=0.318, \mathrm{C}_{\mathrm{H} 2}^{\infty}=0.0526\right)$. An additional concentration of $\mathrm{CO}\left(\mathrm{C}^{\infty} \mathrm{CO}\right)$ is put instantaneously into the mixture after a delay time $t_{\mathrm{CO}}$, whose values have been selected as representative of the $\mathrm{CO}$ addition at: the initial conditions $\left(\begin{array}{ll}0 & \mathrm{~s}\end{array}\right)$, the early reaction startup $(1000 \mathrm{~s})$, in the middle of the reaction startup 
(1250 s) and once the reaction rate is reaching the steady-state (1500 s).

Figures 16, 17, 18 and 19 show the results for the addition of $\mathrm{C}_{\mathrm{CO}}^{\infty}=0.01$ at times $\mathrm{t}_{\mathrm{CO}}=0,1000,1250$ and $1500 \mathrm{~s}$ during the first 50 minutes of the transient PAR performance. On Figures 16 to 18 , the effect of surface poisoning by $\mathrm{CO}$ at

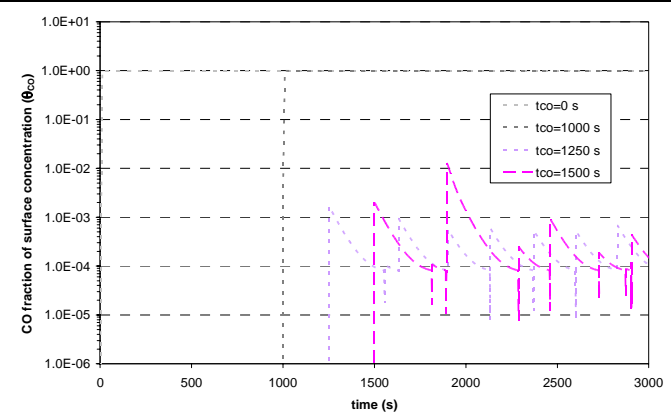

Figure 16. Effect of instantaneous addition of $1 \% \mathrm{CO}$ in the "reference" mixture at different times $t_{\mathrm{CO}}$ during the PAR startup phase. Values of $\theta_{\mathrm{CO}}$ vs time obtained with the standalone model.

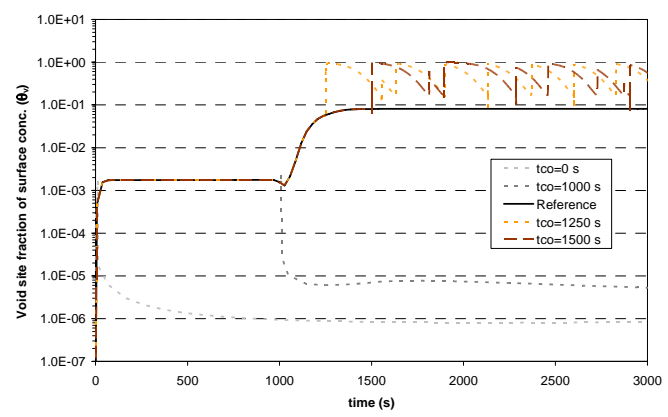

Figure 18. Effect of instantaneous addition of $1 \% \mathrm{CO}$ in the "reference" mixture at different times tco during the PAR startup phase. Values of $\theta \mathrm{v}$ vs time obtained with the standalone model.

The stable $\mathrm{H}-\mathrm{O}$ reaction at the surface is thereby no longer possible to continue, since very few void sites remain available for species adsorption, desorption and reaction $\left(\boldsymbol{\theta}_{\mathrm{v}}\right.$ decreasing below $10^{-5}$ on Figure 18). As a result, plate temperature only peaks up to $\mathrm{T}_{\mathrm{w}}=378 \mathrm{~K}$ by the effect of the starting $\mathrm{H}-\mathrm{O}$ reaction, just before the presence of $\mathrm{CO}$. Figure 19 illustrates the evolution of plate temperature. Low temperature values for $\mathrm{t}_{\mathrm{CO}}=0$ and $\mathrm{t}_{\mathrm{CO}}=1000 \mathrm{~s}$ are indicative of no reaction or early extinguished reactions. On the other hand, once the H-O recombination has been established and plate temperature $T_{w}$ is above some $750 \mathrm{~K}\left(\mathrm{t}_{\mathrm{CO}}=1250,1500 \mathrm{~s}\right)$, even though the initial effect of $\mathrm{CO}$ adsorption is namely the displacement of $\mathrm{O}$ atoms (Figures 16 and 17) out from the surface, this is compensated by the $\mathrm{CO}$ reaction with $\mathrm{O}$ radicals in the surface, because of the higher plate temperature. A large fraction of void sites is formed, enough to sustain the reaction, as Figure 18 shows. As a result, an oscillatory behaviour of the reaction rate is observed: around $660 \mathrm{~g} / \mathrm{h}$ for CO and $750 \mathrm{~g} / \mathrm{h}$ for $\mathrm{H}_{2}$, peaking down with minima in $\theta_{\mathrm{O}}$. Values of $\theta_{\mathrm{CO}}$ lie in the range $10^{-4}-10^{-2}, \theta_{\mathrm{O}}$ oscillates within $10^{-2}-1$ and $\theta_{\mathrm{v}}$ within 0.1-1. Figure 19 explains this behaviour: because of the effect early $\mathrm{CO}$ additions ( $\mathrm{t}_{\mathrm{CO}}=0,1000 \mathrm{~s}$ ) is evidenced by occupying the most of the void sites in the catalyst $\left(\theta_{\mathrm{CO}} \rightarrow 1\right.$ on Figure 16) by displacing the other species when the plate is still at low temperature (for example, $\theta_{\mathrm{O}} \rightarrow 0$ on Figure 17).

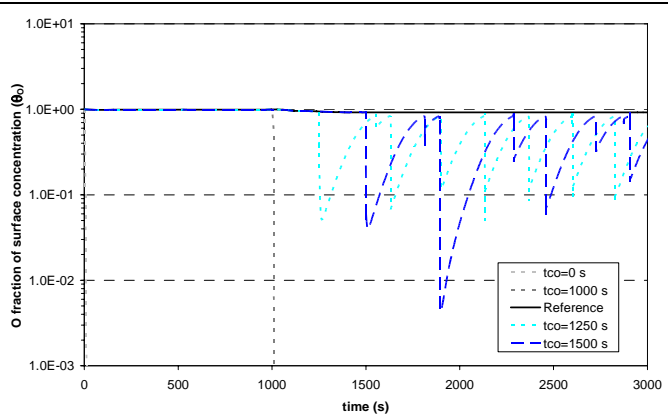

Figure 17. Effect of instantaneous addition of $1 \% \mathrm{CO}$ in the "reference" mixture at different times $t_{\mathrm{CO}}$ during the PAR startup phase. Values of $\theta_{\mathrm{O}}$ vs time obtained with the standalone model.

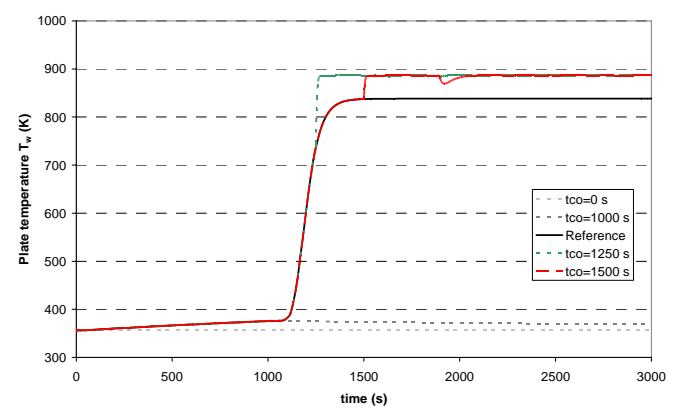

Figure 19. Effect of instantaneous addition of $1 \% \mathrm{CO}$ in the "reference" mixture at different times tco during the PAR startup phase. Values of $\mathrm{T}_{\mathrm{w}}$ vs time obtained with the standalone model.

of $\mathrm{CO}$ reaction, the plate temperature $\mathrm{T}_{\mathrm{w}}$ reaches the value of $887 \mathrm{~K}$, around the value of $900 \mathrm{~K}$ anticipated by (Treviño, 2000 ) in which the competing processes of $\mathrm{CO}$ and $\mathrm{O}_{2}$ adsorption alternate in dominating the reaction rate. The large fraction of void sites $\left(\boldsymbol{\theta}_{\mathrm{v}}\right.$ between 0.1 and 1) assures the reaction to be maintained, also by the energy supply of the $\mathrm{H}_{2-}$ $\mathrm{O}_{2}$ reactions.

In the end, Figures 20, 21, 22 and 23 illustrate the situations when the $\mathrm{CO}$ concentration to be added to the mixture is $\mathrm{C}_{\mathrm{CO}}^{\infty}=0.05$. The effect of increased partial pressure of $\mathrm{CO}$ in the mixture leads to steady-state values in the ignited situations $\left(\mathrm{t}_{\mathrm{CO}}=1250\right.$ and $1500 \mathrm{~s}$ ) equal to $\theta_{\mathrm{CO}}=5.2 \times 10^{-5}$ (Figure 20), $\theta_{\mathrm{O}}=0.69$ (Figure 21), $\theta_{\mathrm{v}}=0.33$ (Figure 22) and at temperatures $\mathrm{T}_{\mathrm{w}}=1063 \mathrm{~K}$ (Figure 23) well above the $900 \mathrm{~K}$ threshold. Hence, reaction rate is fully dominated by the $\mathrm{CO}$ adsorption rate in the steady-state. Recombination rates for $\mathrm{H}_{2}$ and $\mathrm{CO}$ equal $350 \mathrm{~g} / \mathrm{h}$ and $3920 \mathrm{~g} / \mathrm{h}$ respectively. However, transient time to reach the steady-state conditions has been substantially enlarged now up to $4000 \mathrm{~s}$. 


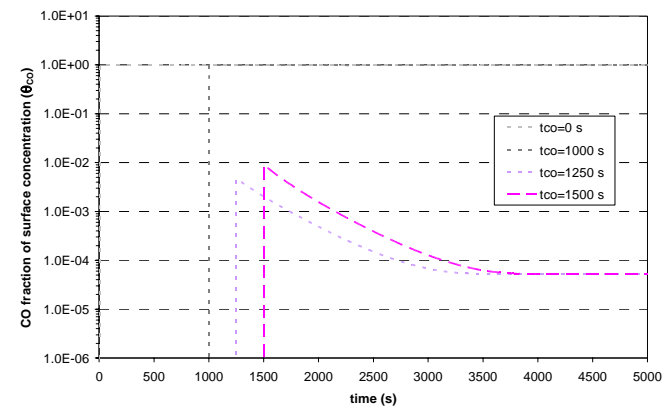

Figure 20. Effect of instantaneous addition of 5\% CO in the "reference" mixture during the PAR startup phase. Values of $\theta_{\mathrm{CO}}$ vs time obtained with the standalone model.

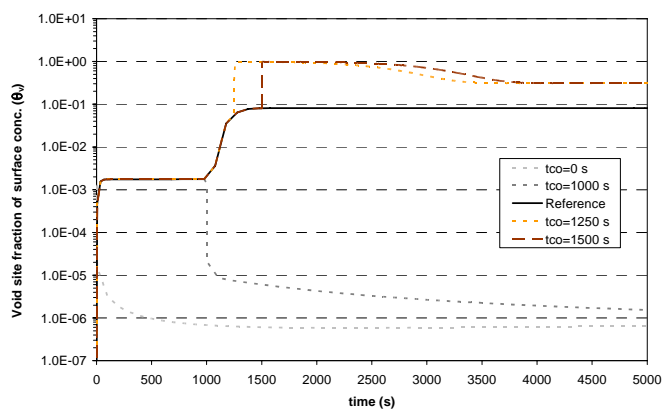

Figure 22. Effect of instantaneous addition of 5\% CO in the "reference" mixture during the PAR startup phase. Values of $\theta_{\mathrm{v}}$ vs time obtained with the standalone model.

\section{Conclusions}

A detailed model for predicting $\mathrm{H}_{2}$ and $\mathrm{CO}$ recombination with parallel plate PARs is introduced in this paper. Models of this kind have been extensively applied to several research activities, mainly in the field of low-temperature, low-emission methane and hydrocarbon combustors, by direct coupling of specific or commercial modules for chemistry kinetics codes with CFD codes.

The model in this paper integrates the associated phenomena in fluid dynamics, heat and mass transfer and surface chemistry being therefore conceived for its coupling with lumped-parameter codes with not excessive penalty in computing time. Even though lumped-parameter codes do not provide with the necessary input to fully characterise the fluid dynamics and transport processes in a PAR, this model provides a promising approach, at least comparable to the commonly used correlations in their ranges of applicability, and allowing further analysis out of these ranges.

Therefore, coupling of this simplified model with the MELCOR code has been successfully performed and tested with minimum modifications. Nevertheless, features of this model allow the detailed exploration of phenomena associated to the surface chemistry, namely those associated to reaction control by species adsorption/desorption, evolution of species populations $\theta_{j}$, etc. Validation of the model against the most important hydrogen PAR qualification tests and correlations has been performed and the effects of heat transfer phenomena have been also analysed.

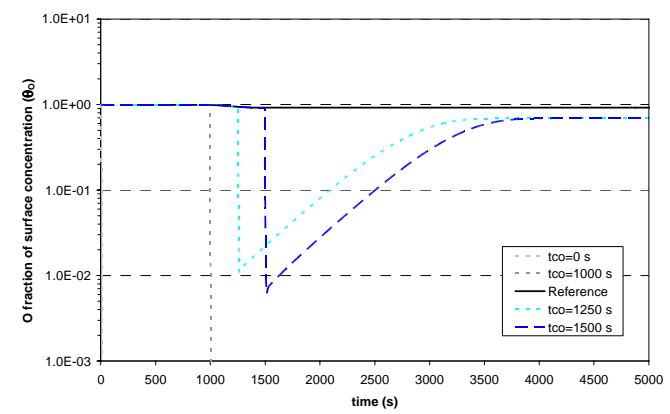

Figure 21. Effect of instantaneous addition of 5\% CO in the "reference" mixture during the PAR startup phase. Values of $\theta_{\mathrm{O}}$ vs time obtained with the standalone model.

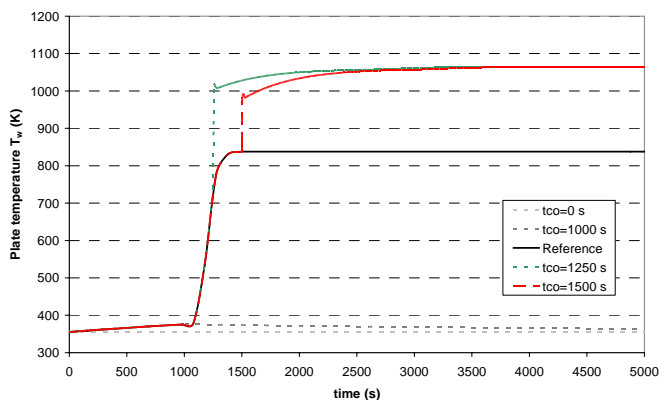

Figure 23. Effect of instantaneous addition of 5\% CO in the "reference" mixture during the PAR startup phase. Values of $\mathrm{T}_{\mathrm{w}}$ vs time obtained with the standalone model.

Additionally, the model introduced in this paper features the ability to analyse the effect of $\mathrm{CO}$ in the mixture, as expected during accidents progressing into the ex-vessel phase. Even though an extensive validation with a complete series of tests has not been performed yet, model results anticipate the effect of $\mathrm{CO}$ in the catalytic combustion chemistry that could lead to catalytic poisoning at low plate temperatures and to additional energy release by $\mathrm{CO}$ recombination otherwise. Increasing relative contribution of $\mathrm{CO}$ reactions has been evidence for increased $\mathrm{CO}$ partial pressure in the mixture and the transient evolution around $T_{w}=900 \mathrm{~K}$ by competition of $\mathrm{CO} / \mathrm{O}_{2}$ adsorption in dominating the reaction rate as anticipated by (Treviño, 2002) has been analysed.

Effects of potential poisoning by species other than CO present in the containment during the ex-vessel phase of a severe accident (boric acid, iodine, other vapours or aerosols) have not been considered so far, but it is expected that a limited extension of the reaction set could be incorporated to account for them with no excessive CPU-time cost.

\section{Acknowledgements}

Authors wished to acknowledge the European Union support by sponsoring the participation of UPM in the HYMI, VOASM, EXPRO, HySafe and SARNET projects within the $4^{\text {th }}, 5^{\text {th }}$ and $6^{\text {th }}$ Framework Programmes of Research, contract references FI4S-CT96-0017 and -0022, EVG1-CT2001-00042, SES6-CT-2004-502630 and FI6O-CT-2004-509065. 


\section{References}

Bachellerie, E. et al., June 2002, State-of-the-art report on passive autocatalytic recombiners. Handbook guide for implementing catalytic recombiners, EC-PARSOAR Project, Technicatome Technical Note TA-185706

Bird, R.B., Stewart, W.E. and Lightfoot, E.D., 1960, Transport Phenomena, Wiley-Interscience, New York

Blanchat, T.K. and Malliakos, A., 1998, Performance testing of passive autocatalytic recombiners, NUREG/CR-6580, SAND $97-2632$

Carcassi, M. and Bazzicchi, A., 1997, Empirical correlations for PAR performances, Universitá di Pisa, CONT-HYMI(97)-D007

Deutschmann, O., Schmidt, R., Behrendt, F. and Warnatz, J., 1996, Numerical modeling of catalytic ignition, Proceedings of The Combustion Institute 26, pp. 1747-1754

Elenbaas, W., 1942, Heat dissipation of parallel plates by free convection, Physica IX, no 1, 1-28

Fischer, K., 1995, Qualification of passive catalytic module for hydrogen mitigation, Nuclear Technology 112, 58-62

Gauntt, R. et al., 2000, MELCOR computer code manuals, NUREG/CR-6119

Heitsch, M., 2000, Fluid-dynamic analysis of a catalytic recombiner to remove hydrogen, Nuclear Engineering and Design 201, 1-10

Hellsing, B., Kasemo, B. and Zhdanov, V.P., 1991, Kinetics of the hydrogen-oxygen reaction on platinum, Journal of Catalysis 132, 210-228

Incropera, F.P. and DeWitt, D.P., 2001, Fundamentals of Heat and Mass Transfer, John Wiley \& Sons, Inc.

Kanzleiter, T., 1997(a), Multiple hydrogen-recombiner experiments performed in the Battelle Model Containment: multi-reco experiments Zx02 and Zx05, Technical Report BF-R40.084-01, CONT-HYMI(97)-P004

Kanzleiter, T., 1997(b), Multiple hydrogen-recombiner experiments performed in the Battelle Model Containment: multi-reco experiment Zx08, Technical Report BF-V68.405-01, CONT$\operatorname{VOASM}(97)-\mathrm{P} 001$

Kanzleiter, T., 1997(c), Multiple hydrogen-recombiner experiments performed in the Battelle Model Containment: multi-reco experiments Zx03 and Zx04, Technical Report BF-V68.405-02, CONT-VOASM(97)-D005

Kumar, R.K., Koroll, G.W., Heitsch, M. and Studer, E., 2000, Carbon monoxide - hydrogen combustion characteristics in severe accident containment conditions. Final report, OECD/NEA/CSNI/R(2000)10
LAPack Linear Algebra Package, version 3.0 http://www.netlib.org/lapack, May 2000

Martín-Valdepeñas, J.M., 2004, Modelos numéricos acoplados a un código fluidodinámico para el análisis del riesgo de combustión de hidrógeno en contenciones ( $\mathrm{PhD}$ Thesis), Universidad Politécnica de Madrid

McBride, B.J. and Gordon, S., 1996, Computer program for calculation of complex chemical equilibrium compositions and applications, NASA Reference Publication 1311

Meglicki, Z., 2001, Advanced Scientific Computing (Lecture Notes), Indiana University

Mellado, J.D., 2002, La ignición del hidrógeno en capas de mezcla y paredes catalíticas ( $\mathrm{PhD}$ Thesis), Universidad Carlos III de Madrid

Mohaved, M.A., September 1994, Recombiner model for lumpedparameter codes validation and application, in International Workshop on Hydrogen Research for Reactor Safety, Münich, Germany

Mohaved, M.A., August 1999, Application and limitation of lumpedparameter and $3 \mathrm{D}$ codes in nuclear safety research, in $15^{\text {th }}$ SMIRT Seoul, S Korea, pp. XI/165-172

Reinecke, E.A., Tragsdorf, I.M. and Gierling, K., 2004, Studies on innovative hydrogen recombiners as safety devices in the containments of light water reactors, Nuclear Engineering and Design 230, 49-59

Rinnemo, M., Kulginov, D., Johansson, S., Wong, K.L., Zhdanov, V.P. and Kasemo, B., 1997, Catalytic ignition in the CO-O reaction on platinum: experiment and simulations, Surface Science 376, 297-309

Sher, R., Trotter, J.D. and Leaver, D.E., April 1997, Passive autocatalytic recombiners for mitigating hydrogen concentrations following design-basis accidents in nuclear power plants, in $5^{\text {th }}$ Meeting on Nuclear Thermalhydraulics, Operations and Safety

Treviño, C. and Prince, J.C., 1999, An asymptotic analysis of catalytic ignition at a stagnation-point flow, Combustion Theory Modelling 3, 469-477

Treviño, C. and Prince, J.C., 2000, Catalytic combustion of dry carbon monoxide by external power activation, Surface Science $449,61-74$ 